\title{
Fine tuning of emission through the engineering of colloidal
}

\section{crystals}

Jean-François Dechézelles ${ }^{1}$, Tangi Aubert ${ }^{2}$, Fabien Grasset ${ }^{2}$, Stéphane Cordier $^{2}$, Carlos Barthou $^{3}$, Catherine Schwob ${ }^{3}$, Agnès Maître ${ }^{3}$, Renaud A. L. Vallée ${ }^{1}$, Henri Cramail ${ }^{4}$ and Serge Ravaine ${ }^{1, *}$

${ }^{1}$ Université Bordeaux 1, Centre de Recherche Paul Pascal, 115 avenue Dr Schweitzer, 33600 Pessac, France

${ }^{2}$ Université de Rennes 1, Unité Science Chimiques de Rennes, UMR 6226 CNRS-UR1, Campus de Beaulieu, CS74205, F-35042 Rennes cedex, France

${ }^{3}$ Institut des NanoSciences de Paris, UMR - CNRS 7588, Université Pierre et Marie Curie, Campus Boucicaut, 140 rue de Lourmel, 75015, France

${ }^{4}$ Université Bordeaux 1, Laboratoire de Chimie des Polymères Organiques, UMR 5629 CNRS ENSCPB, 16 avenue Pey-Berland, 33607 Pessac, France

* Corresponding author. Tel.: +33-556-84-56-67; fax: +33-556-84-56-00.

E-mail address: ravaine@crpp-bordeaux.cnrs.fr.

\begin{abstract}
We describe the preparation and characterization of photonic colloidal crystals from silica spheres with incorporated luminescent $\left[\mathrm{Mo}_{6} \mathrm{Br}_{14}\right]^{2-}$ cluster units. These structures exhibit strong angle-dependent luminescent properties. The incorporation of one or several planar defects in the periodic structures gives rise to the creation of a pass band in the stopband. In the energy range of this pass band, an increase of the emission intensity has been found.
\end{abstract}




\section{Introduction}

Photonic crystals (PCs) are a class of artificial structures with a periodic dielectric function in one, two, or three dimensions, in which the propagation of electromagnetic waves within a certain frequency band is forbidden. This forbidden frequency band has been dubbed photonic band gap (PBG). The position, width, depth, and shape of the PBG strongly depend on the periodicity, symmetry properties, dielectric constant contrast, and internal lattice structure of the unit cell. There is a common belief that PCs will perform many functions with light that ordinary crystals do with electrons.

Various important scientific and engineering applications such as control of spontaneous emission, ${ }^{1-11}$ zero-threshold lasing, ${ }^{12}$ very sharp bending of light, ${ }^{13-14}$ lightemitting diodes, ${ }^{15-16}$ and so on, have been demonstrated by utilizing the photonic bandgap and/or light-emitters. Especially, a stopband, i.e. an incomplete photonic bandgap, can inhibit light propagation in a certain direction for a given frequency. Many groups have reported that PCs can modify significantly the emission characteristics of emitters (organic dyes, ${ }^{5,17}$ semiconductors, ${ }^{7,18}$ rare earth doped particles, ${ }^{19-20}$ etc.) as the emission wavelength of the optically-active material overlaps the stopband. In most of these studies, the emitters have been incorporated within pre-fabricated PCs owing to a simple infiltration process. As the efficiency of controlled emission is highly dependent on the organization of the PCs, which may get disturbed by the solvent used, and the homogeneous infiltration of the dyes, we chose to incorporate the emitters in the silica particles themselves, which were thus used to fabricate luminescent colloidal crystals following the strategy reported by only a few groups. ${ }^{10,21-22}$

Moreover, more emphasis in the PCs research field is placed on the incorporation of point, channel, and planar defects within the PCs structures for the creation of localized points and pathways for photons. With regard to the planar defects, which can be introduced within PCs by chemical vapor deposition, ${ }^{23-24}$ spin-coating, ${ }^{25-26}$ or the Langmuir-Blodgett (LB) 
technique, ${ }^{27-31}$ the emergence of a localized state for photons within the stopband, known as a defect mode, has been revealed. The obtained heterostructures present a dip, also called pass band, inside the stop band in the extinction spectrum. As far as we know, there is only one report on the spectral narrowing of emission in self-assembled colloidal photonic superlattices, though no clear effect of the pass band was observed in the fluorescence emission spectrum. ${ }^{32}$ This situation motivated us to investigate the influence of the introduction of one or several defect layers inside a 3D colloidal crystal on the emission spectrum of the incorporated emitters.

In this paper, we present a study of stop band / pass band effects on spontaneous emission of $\left[\mathrm{Mo}_{6} \mathrm{Br}_{14}\right]$ clusters-doped silica particles organized in 3D colloidal crystals. Let us recall that $\left[\left(\mathrm{Mo}_{6} \mathrm{~L}_{8}^{\mathrm{i}}\right) \mathrm{L}_{6}^{\mathrm{a}}\right]$ cluster units (Figure 1a, $\mathrm{L}=$ halogen and or chalcogen), constitute the basic building blocks in molybdenum octahedral cluster chemistry. The $\mathrm{Mo}_{6}$ cluster is face-capped by eight inner ligands $\left(\mathrm{L}^{\mathrm{i}}\right)$ and is additionally bonded to six apical ligands $\left(\mathrm{L}^{\mathrm{a}}\right) .{ }^{33-34}$ The physical properties of $\mathrm{Mo}_{6}$ solid-state compounds are related to the number of electrons available for metal-metal bonding within the cluster (valence electron count, VEC). Mocentered electrons are located on twelve metal-metal bonding molecular orbitals of the molecular orbital diagram. Their full occupation leads to a closed-shell configuration with a VEC of $24 .{ }^{35}$ Using high temperature synthesis, it turns out that halogen ligands favor the formation of solid-state molecular compounds based on $\left[\mathrm{Mo}_{6} \mathrm{X}_{8}^{\mathrm{i}} \mathrm{X}_{6}^{\mathrm{a}}\right]^{2-}(\mathrm{X}=\mathrm{Cl}, \mathrm{Br}, \mathrm{I})$ units with VEC values of 24 that can be discrete or poorly interconnected within the solid. The disssolution of inorganic solid-state halide precursors affords nanometric $\left[\mathrm{Mo}_{6} \mathrm{X}_{14}\right]^{2-}$ anionic units that exhibit interesting structural, photophysical, and redox properties that can be used for the formation and organization of supramolecular assemblies as well as hybrid materials. ${ }^{36-39}$ For instance, the large emission region of the $\left[\mathrm{Mo}_{6} \mathrm{X}_{14}\right]^{2-}$ anion in the red and near infrared $(580-900 \mathrm{~nm})^{40-42}$ is particularly interesting for biotechnology applications. In 
this frame, some of us recently prepared by water in oil microemulsion synthesis luminescent $\mathrm{Cs}_{2} \mathrm{Mo}_{6} \mathrm{X}_{14} @ \mathrm{SiO}_{2}$ and bifunctionnal luminescent magnetic $\mathrm{Fe}_{2} \mathrm{O}_{3}-\mathrm{Cs}_{2} \mathrm{Mo}_{6} \mathrm{X}_{14} @ \mathrm{SiO}_{2}$

nanoparticles containing $\left[\mathrm{Mo}_{6} \mathrm{X}_{14}\right]^{2-}$ unit as red inorganic dye. ${ }^{43-44} \mathrm{Cs}_{2} \mathrm{Mo}_{6} \mathrm{Br}_{14}$ precursors were encapsulated in silica by a classical sol-gel synthetic procedure and the obtained colloidal spheres were organized by the LB technique to elaborate 3D colloidal crystals. Heterostructures containing one or three planar defects made of silica spheres with a different size were also fabricated. We clearly observed that the emission of the incorporated light sources was inhibited by the presence of a stop band and was enhanced in the spectral region of a pass band.

\section{Experimental}

\section{$\mathrm{Cs}_{2} \mathrm{Mo}_{6} \mathrm{Br}_{14}$ clusters synthesis}

The $\mathrm{Cs}_{2} \mathrm{Mo}_{6} \mathrm{Br}_{14}$ ternaries were synthesized from a stoichiometric amount of $\mathrm{CsBr}$ and $\mathrm{MoBr} 2$ binary halides according to the procedure described in the literature. ${ }^{45-46}$

\section{Fabrication of the $\mathrm{Cs}_{2} \mathrm{Mo}_{6} \mathrm{Br}_{14} @ \mathrm{SiO}_{2}$ colloidal particles}

$\mathrm{Cs}_{2} \mathrm{Mo}_{6} \mathrm{Br}_{14} @ \mathrm{SiO}_{2}$ spheres with a mean diameter of $270 \pm 15 \mathrm{~nm}$ and $330 \pm 15 \mathrm{~nm}$ were synthesized following the well-known Stöber-Fink-Bohn method. ${ }^{47}$ As an example, for the synthesis of the $330 \mathrm{~nm}$ spheres, $100 \mathrm{mg}$ of $\mathrm{Cs}_{2} \mathrm{Mo}_{6} \mathrm{Br}_{14}$ clusters, $195 \mathrm{ml}$ of absolute ethanol (Prolabo), $11 \mathrm{ml}$ of ammonia (29\% in water, J.T. Baker), $29 \mathrm{ml}$ of water were introduced in a $500 \mathrm{~mL}$ three-neck round flask equipped with a refrigerating system and stirred at $40^{\circ} \mathrm{C}$ at $400 \mathrm{rpm}$ to homogenize. $16.5 \mathrm{ml}$ of tetraethoxysilane (TEOS, 99\%) (Fluka) were then introduced and the solution was left under stirring during 24 hours. A transmission electron microscopy (TEM) picture of the 270 nm $\mathrm{Cs}_{2} \mathrm{Mo}_{6} \mathrm{Br}_{14} @ \mathrm{SiO}_{2}$ spheres is shown in Figure $1 \mathrm{~b}$. The good monodispersity in size of the particles can be seen. Nevertheless, the $\mathrm{Mo}_{6} \mathrm{Br}_{14}$ units 
cannot be distinguished inside the $\mathrm{SiO}_{2}$ particles due to the strong absorption of the mineral particles.

The above suspension of $330 \mathrm{~nm}$ particles was used as a seed for the growth of silica in order to get particles with a final diameter of $460 \pm 25 \mathrm{~nm}$. Typically, $250 \mathrm{~mL}$ of the suspension of seeds were introduced in a $500 \mathrm{~mL}$ three-neck round flask. A solution of 6.5 $\mathrm{mL}$ of TEOS diluted in $25 \mathrm{~mL}$ of absolute ethanol was added dropwise at an addition rate of 2 $\mathrm{mL} \cdot \mathrm{h}^{-1}$ under stirring at $400 \mathrm{rpm}$ and at room temperature. Synthesis was carried out for 24 hours.

In order to use the $\mathrm{Cs}_{2} \mathrm{Mo}_{6} \mathrm{Br}_{14} @ \mathrm{SiO}_{2}$ colloidal beads as building units to elaborate colloidal crystals by the LB technique, their surface was functionalized with aminopropyltriethoxysilane (99\%, Aldrich) as previously described. ${ }^{48}$

\section{Fabrication of the colloidal crystals}

Multilayer colloidal crystals were deposited by the Langmuir-Blodgett technique onto glass substrates $(24 \mathrm{~mm} \times 60 \mathrm{~mm})$. Details of the fabrication have been already published. ${ }^{48} 3 \mathrm{D}$ colloidal crystals including one or three defect layers of particles of larger size were elaborated by alternately depositing 5 layers of $330 \mathrm{~nm} \mathrm{Cs}_{2} \mathrm{Mo}_{6} \mathrm{Br}_{14} @ \mathrm{SiO}_{2}$ particles (host particles), and one layer of 460 nm $\mathrm{Cs}_{2} \mathrm{Mo}_{6} \mathrm{Br}_{14} @ \mathrm{SiO}_{2}$ spheres (guest spheres).

The 3D heterostructures are stable over years and can be manipulated without any damage if one takes care not to rub them up.

\section{Characterizations}

The size of the colloidal particles was determined statistically by analyzing TEM pictures taken with a Hitachi H-600 microscope. 
Scanning electron microscopy (SEM) observations of the photonic crystals were performed with a JEOL JSM-6700F scanning electron microscope operating at $10 \mathrm{kV}$. The specimens were carbon-coated and simply cut into pieces using a glass cutter prior to examination.

Ultra-violet visible (UV-vis) extinction spectra were obtained by recording the transmitted intensity at normal incidence on a UV4 Spectrometer from Unicam. The extinction spectrum is defined as $1-\mathrm{T}$ where $\mathrm{T}$ is the transmitted intensity spectrum normalized to the incident intensity spectrum on the sample. For specular reflection, samples were illuminated with a fibered and collimated halogen source covering the whole $350-800 \mathrm{~nm}$ spectral range. The reflected light was collected by a second optical fiber symmetric to the first one. The fibers were mounted on rotating stages allowing for a precise selection of the incident and collection angles. The light spot on the opal had a size of $4 \mathrm{~mm}^{2}$ (at $20^{\circ}$ incidence) and the distance between the sample and the optical fiber was $10 \mathrm{~cm}$. As for the extinction spectra, specular reflexion spectra are normalized to the incident light spectrum.

The photoluminescence (PL) emission spectra were obtained by exciting the samples by the $337 \mathrm{~nm}$ nitrogen laser line (Laser Photonics LN 1000, $1.4 \mathrm{~mJ}$ pulse energy, $0.6 \mathrm{~ns}$ pulse duration). The emitted light from the sample, collected at $8 \mathrm{~cm}$ by an optical fiber on the same side as the excitation, was analyzed with a Jobin-Yvon Spectrometer HR460 and a multichannel CCD detector (2000 pixels). The spectrometer was corrected for wavelength dependence of the transmission of the polychromator and the sensitivity of the detector. This setup has a resolution of $0.3 \mathrm{~nm} /$ point for a $30 \mu \mathrm{m}$ slit.

\section{Simulations}

Finite-difference time-domain (FDTD) simulations ${ }^{49}$ of the extinction, reflection spectra of the various photonic architectures experimentally investigated were performed, integrated in a freely available software package with sub-pixel smoothing for increased accuracy. ${ }^{50}$ The computational cell, in which the incoming wave propagates along the $\mathrm{z}$ direction at normal 
incidence, has been implemented with periodic boundary conditions in $\mathrm{x}$ and $\mathrm{y}$ directions and perfectly matched layers (PMLs) in the $\mathrm{z}$ direction. The resolution of the grid has been refined such that the convergence of the results was ensured. To be in close agreement with the experimental conditions, the opals have been represented by monodiperse spheres of given size $(330 \mathrm{~nm})$ and dielectric constant $\varepsilon=2.1$ arranged along a face-centered cubic (fcc) lattice. The lattice has been truncated to 25 (for Figure 2c) or 10 (for Figure 3b) planes normal to the direction [111], and the resulting crystal was set on a substrate with a dielectric constant of 2.3, which corresponds to the glass slides that were used, extending to the PMLs in the $\mathrm{z}$ direction. In case of a defect layer of larger spheres (with a diameter of 1.5 larger than the host particles) has been introduced between two stacks of 5 layers of host particles on the experimental side, we represented this layer on the simulation side by a bloc of the appropriate thickness with an effective refractive index $n_{e}=1.35$.

\section{Results and discussion}

The luminescence properties of the $\mathrm{Cs}_{2} \mathrm{Mo}_{6} \mathrm{Br}_{14} @ \mathrm{SiO}_{2}$ particles were first analyzed. Figure 2a shows the room-temperature PL spectra measured under $337 \mathrm{~nm}$ excitation of aqueous solutions of the particles at various concentrations. The spectra show a broad band

centered around $705 \mathrm{~nm}$ and exhibit a similar shape to those of the starting compounds, ${ }^{43}$ evidencing that the emission properties of clusters are preserved when incorporated inside the silica particles.

The photonic crystals fabricated with the $\mathrm{Cs}_{2} \mathrm{Mo}_{6} \mathrm{Br}_{14} @ \mathrm{SiO}_{2}$ particles display a strong iridescence in the visible region of the spectrum, which indicates the presence of a photonic stop band due to the regular ordering of the building spherical units. In fact, the good crystalline quality of a crystal made of 25 layers of $330 \mathrm{~nm}$ particles can be seen on the SEM side view shown in Figure 2b. Figure 2c shows the optical extinction / reflection spectra of the 
crystal (solid lines), taken at various incidence angles (from $0^{\circ}$ to $40^{\circ}$ ). One main peak, which shifts to shorter wavelength when the angle of incidence is increased, is observed according to Bragg-Snell diffraction law:

$$
\lambda_{\max }=2 \sqrt{\frac{2}{3}} D \sqrt{n_{e}^{2}-\sin ^{2} \alpha}
$$

where $\lambda_{\max }$ is the Bragg diffracted wavelength, $\alpha$ is the angle between the [111] direction and the incident beam, $\mathrm{D}$ is the diameter of the colloidal particles and $\mathrm{n}_{\mathrm{e}}$ is the effective refractive index of the crystal at the wavelength of interest. Spectra were simulated using the FDTD method. Calculated spectra (dashed lines) are plotted along the experimental ones in Figure 2c. Note that the vertical axis is arbitrarily scaled and the spectra are arbitrarily shifted in order to clearly distinguish them, as a function of angle. A good agreement between theoretical and experimental data can be observed.

The successful engineering of the crystal is clearly shown in Figure 2c, as the pseudogap maximum overlaps completely $\left(\alpha=0,20,25,30^{\circ}\right)$ or partially $\left(\alpha=35^{\circ}\right)$ the emission band of the $\mathrm{Cs}_{2} \mathrm{Mo}_{6} \mathrm{Br}_{14} @ \mathrm{SiO}_{2}$ particles, represented in the figure as a grey vertical rectangle. Therefore, one should expect the emission spectrum changes when the detection angle is modified. In order to verify this point, we conducted an angle-resolved emission study during which the excitation wavelength was chosen to be $337 \mathrm{~nm}$, which is outside the stop band of the crystal in order to penetrate well into the sample and interact with the emitters. Figure $2 \mathrm{~d}$ shows the emission spectra recorded at six different detection angles (solid lines), while the experimental extinction / reflection spectra of the sample are also shown (dashed lines). A profound dip in the emission band is observed. Its position shifts to shorter wavelengths when $\alpha$ increases, coinciding with the spectral position of the stopband. This indicates that an inhibition of the light emission from the $\mathrm{Cs}_{2} \mathrm{Mo}_{6} \mathrm{Br}_{14} @ \mathrm{SiO}_{2}$ particles occurs due to a low density of photonic states in the wavelength range of the stopband. A maximum inhibition of 
the luminescent emission of $\sim 35 \%$ was estimated at $\alpha=0^{\circ}$, whereas the emission band of the $\mathrm{Cs}_{2} \mathrm{Mo}_{6} \mathrm{Br}_{14} @ \mathrm{SiO}_{2}$ particles is unaffected at $\alpha=40^{\circ}$ as the stopband is brought completely out of the emission range.

In order to investigate the influence of a pass band on the emission spectrum of the $\mathrm{Cs}_{2} \mathrm{Mo}_{6} \mathrm{Br}_{14} @ \mathrm{SiO}_{2}$ particles, we exploited our capability to build multilayer colloidal crystals in a controlled manner with the Langmuir-Blodgett technique. We engineered a colloidal crystal composed by one layer of 460 nm $\mathrm{Cs}_{2} \mathrm{Mo}_{6} \mathrm{Br}_{14} @ \mathrm{SiO}_{2}$ spheres embedded between two stacks of five layers of $330 \mathrm{~nm} \mathrm{Cs}_{2} \mathrm{Mo}_{6} \mathrm{Br}_{14} @ \mathrm{SiO}_{2}$ particles. The crystal's structure can be described as $(330)_{5} /(460)_{1} /(330)_{5}$ by listing the sphere size from bottom to top. Both the defect layer and the good crystalline quality of the sample can be seen on the SEM side view shown in Figure 3a. The insertion of such a defect layer induces the appearance of localized states for photons within the L pseudo-gap of the host particles structure. Accordingly, a pass band is created within the stop band. On the basis of the particle diameters of the guest and host particles used for the preparation of the sample, the pass band position is expected to overlap the emission profile of the colloidal building units. This has been verified experimentally by recording the extinction / reflection spectra of the sandwich-like crystal as a function of angle while tilting the sample over the $\Gamma L$ direction. Indeed, Figure $3 b$ shows that these spectra (solid lines) exhibit a dip within the pseudogap, which shifts to the blue and passes through the emission range of the $\mathrm{Cs}_{2} \mathrm{Mo}_{6} \mathrm{Br}_{14} @ \mathrm{SiO}_{2}$ particles as $\alpha$ increases. Calculated spectra (dashed lines) are also plotted along the experimental ones in Figure 3b. Here again, the simulations fit the experimental ones accurately in all cases. Figure $3 \mathrm{c}$ shows the emission (solid lines) and extinction / reflection (dashed lines) spectra of the sandwich-like crystal recorded at six different detection angles. For $0^{\circ} \leq \alpha \leq 35^{\circ}$, both an inhibition of the emission in the dielectric and air band regions and an exaltation within the pass band are clearly 
observed, as the result of the redistribution of the photonic local density of states. Only a weak shoulder in the PL spectrum around $650 \mathrm{~nm}$ is visible for $\alpha=40^{\circ}$, as a result of the blue shifting of the pass band towards the low wavelength edge of the emission band induced by the tilting of the sample. To quantify the effects of the $(330)_{5} /(460)_{1} /(330)_{5}$ crystal on the emission spectra, we took the ratio of the emission spectra to the spectrum recorded from a reference sample made of 10 layers of $270 \mathrm{~nm} \mathrm{Cs} \mathrm{Mo}_{6} \mathrm{Br}_{14} @ \mathrm{SiO}_{2}$ spheres, which exhibits a photonic band gap at $595 \mathrm{~nm}$ (not shown). We thus obtained the relative intensity spectra displayed in Figure $3 \mathrm{~d}$. For $\alpha=0^{\circ}$, the data clearly show a $15 \%$ attenuation of the emission in the dielectric and air band regions as well as a $8 \%$ enhanced emission in the pass band region. The simultaneous observation of attenuation and enhancement means that the effect of the PC is not a simple filter action.

We further took advantage of the versatility of the Langmuir-Blodgett technique by engineering a photonic heterostructure made by alternated deposition of stacks (A) made of five layers of $330 \mathrm{~nm} \mathrm{Cs}_{2} \mathrm{Mo}_{6} \mathrm{Br}_{14} @ \mathrm{SiO}_{2}$ particles with one monolayer (B) of $460 \mathrm{~nm}$ $\mathrm{Cs}_{2} \mathrm{Mo}_{6} \mathrm{Br}_{14} @ \mathrm{SiO}_{2}$ particles. Figure 4a shows a SEM side view of a $\mathrm{A}(\mathrm{BA})_{3}$ heterostructure. The thickness of each stack is controlled at the layer level as the number of deposited layers matches perfectly with the predefined value of transfer cycles. The overall thickness of the sample is uniform despite the presence of defect layers B of larger silica particles which periodically separate the A substructures. The periodic alternation between $\mathrm{A}$ and $\mathrm{B}$ substructures gives rise to a superlattice, whose periodic parameter corresponds to the sum of the thicknesses of stacks A and B. We have recently shown that the pass band becomes wider as the layering is repeated. ${ }^{30}$ The comparison of the extinction spectra of $\mathrm{A}(\mathrm{BA})_{1}$ and $\mathrm{A}(\mathrm{BA})_{3}$ heterostructures taken at normal incidence $\left(\alpha=0^{\circ}\right)$ and shown in Figure $4 \mathrm{~b}$ confirms this assertion, as the width of the defect state of the latter is larger than for the $\mathrm{A}(\mathrm{BA})_{1}$ crystal. In agreement with our previous observations, ${ }^{30}$ weak oscillations are also visible inside the 
passband of the $\mathrm{A}(\mathrm{BA})_{3}$ sample. They can be assimilated to minibands, which result from the coupling of the individual defect modes in the heterostructure. Figure $4 \mathrm{~b}$ further illustrates the influence of the structure of the colloidal crystals on the emission characteristics of their building units. An enhancement of the emission is observed between $700 \mathrm{~nm}$ and $770 \mathrm{~nm}$ in the PL spectrum of the $\mathrm{A}(\mathrm{BA})_{3}$ heterostructure, i.e. in the whole spectral zone of the pass band. One should also note a slight inhibition of the emission at $730 \mathrm{~nm}$ and $765 \mathrm{~nm}$, which correspond to the spectral positions of the minibands, which thus act as stopbands.

\section{Conclusions}

In summary, we have engineered colloidal crystals from silica spheres with

incorporated luminescent $\left[\mathrm{Mo}_{6} \mathrm{Br}_{14}\right]^{2-}$ cluster units. An inhibition of the emission intensity from the light sources was observed in the spectral region of the stop band, which was found to nicely correspond and follow the Bragg-Snell law as the angle between the [111] direction and the incident beam was varied. Heterostructures containing one or three planar defects displayed increased emission in the spectral region of the pass band. The $3 \mathrm{D}$ photonic colloidal structures investigated here are very promising for both basic and applied research related to the confinement and exaltation of spontaneous emission in given frequency ranges and thus are good candidates for low-threshold and/or single mode photonic crystal lasers.

\section{Acknowledgements}

The authors thank B. Agricole (CRPP) and E. Sellier (CREMEM, Talence) for Langmuir-Blodgett experiments and SEM observations, respectively. 


\section{References}

1. S. Fan, P. R. Villeneuve, J. D. Joannopoulos and E. F. Schubert, Phys. Rev. Lett., 1997, 78, 3294.

2. E. P. Petrov, V. N. Bogomolov, I. I. Kalosha and S. V. Gaponenko, Phys. Rev. Lett., 1998, 81, 77.

3. S. V. Gaponenko, V. N. Bogomolov, E. P. Petrov, A. M. Kapitonov, D. A. Yarotsky, I. I. Kalosha, A. A. Eychmueller, A. L. Rogach, J. McGilp, U. Woggon and F. Gindele, J. Lightwave Technol., 1999, 17, 2128.

4. S. V. Gaponenko, V. N. Bogomolov, E. P. Petrov, A. M. Kapitonov, A. A. Eychmueller, A. L. Rogach, I. I. Kalosha, F. Gindele and U. Woggon, J. Lumin., 2000, 87, 152.

5. L. Bechger, P. Lodahl and W. L. Vos, J. Phys. Chem. B, 2005, 109, 9980.

6. M. Megens, J. E. G. J. Wijnhoven, A. Lagendijk and W. L. Vos, J. Opt. Soc. Am. B, 1999, 16, 1403.

7. P. Lodahl, A. F. van Driel, I. S. Nikolaev, A. Irman, X. Overgaag, D. Vanmaekelbergh and W. L. Vos, Nature, 2004, 430, 654.

8. A. F. Koenderink and W. L. Vos, Phys. Rev. Lett., 2003, 91, 213902.

9. R. C. Schroden, M. Al-Daous and A. Stein, Chem. Mater., 2001, 13, 2945.

10. F. Fleischhaker and R. Zentel, Chem. Mater., 2005, 17, 1346.

11. M. Müller, R. Zentel, T. Maka, S. G. Romanov and C. M. Sotomayor Torres, Chem. Mater., 2000, 12, 2508.

12. L. K. Teh, C. C. Wong, H. Y. Yang, S. P. Lau and S. F. Yu, Appl. Phys. Lett., 2007, $91,161116$.

13. A. Chutinan and S. Noda, Appl. Phys. Lett., 1999, 75, 3739. 
14. S. Y. Lin, E. Chow, V. Hietala, P. R. Villeneuve and J. D. Joannopoulos, Science, 1998, 282, 274.

15. M. Boroditsky, T. F. Krauss, R. Coccioli, R. Vrijen, R. Bhat and E. Yablonovitch, Appl. Phys. Lett., 1999, 75, 1036.

16. Y. R. Do, Y. C. Kim, Y. W. Song, C. Cho, H. Jeon, Y. J. Lee, S. H. Kim and Y. H. Lee, Adv. Mater., 2003, 15, 1214.

17. B. Kolaric, K. Baert, M. Van der Auweraer, R. A. L. Vallée and K. Clays, Chem. Mater., 2007, 19, 5547.

18. Y.A. Vlasov, K. Luterova, I. Pelant, B. Honerlage and V. N. Astratov, Appl. Phys. Lett., 1997, 71, 1616.

19. A. Chiappini, C. Armellini, A. Chiasera, M. Ferrari, Y. Jestin, M. Mattarelli, M. Montagna, E. Moser, G. Nunzi Conti, S. Pelli, G. C. Righini, M. Clara Goncalves and R. M. Almeida, J. Non-Cryst. Solids, 2007, 353, 674.

20. Y.-S. Lin, Y. Hung, H.-Y. Lin, Y.-H. Tseng, Y.-F. Chen and C.-Y. Mou, Adv. Mater., 2007, 19, 577.

21. R. V. Nair, R. Vijaya, K. Kuroda and K. Sakoda, J. Appl. Phys., 2007, 102, 123106.

22. Y. Li, T. Kunitake, S. Fujikawa and K. Ozasa, Langmuir, 2007, 23, 9109.

23. E. Palacios-Lidon, J. F. Galisteo-Lopez, B. H. Juarez and C. Lopez, Adv. Mater., 2004, 16,341 .

24. N. Tétreault, A. Mihi, H. Miguez, I. Rodriguez, G. A. Ozin, F. Meseguer and V. Kitaev, Adv. Mater., 2004, 16, 346

25. L. Wang, Q. Yan and X. S. Zhao, Langmuir, 2006, 22, 3481.

26. R. Pozas, A. Mihi, M. Ocaña and H. Míguez, Adv. Mater., 2006, 18, 1183.

27. K. Wostyn, Y. Zhao, G. de Schaetzen, L. Hellemans, N. Matsuda, K. Clays and A. Persoons, Langmuir, 2003, 19, 4465. 
28. Y. Zhao, K. Wostyn, G. de Schaetzen, K. Clays, L. Hellemans, A. Persoons, M.

Szekeres and R.A. Schoonheydt, Appl. Phys. Lett., 2003, 82, 3764.

29. P. Massé, S. Reculusa, K. Clays and S. Ravaine, Chem. Phys. Lett., 2006, 422, 251.

30. P. Massé, G. Pouclet and S. Ravaine, Adv. Mater., 2008, 20, 584.

31. P. Massé, R. A. L. Vallée, J.-F. Dechézelles, J. Rosselgong, E. Cloutet, H. Cramail, X.

S. Zhao and S. Ravaine, J. Phys. Chem. C, 2009, 113, 14487.

32. K. Baert, K. Song, R. A. L. Vallée, M. Van der Auweraer and K. Clays, J. Appl. Phys., 2006, 100, 123112.

33. H. Schaefer and H. G. Schnering, Angew. Chem. 1964, 76, 833.

34. S. Cordier, K. Kirakci, D. Méry, C. Perrin and D. Astruc, Inorganica Chimica Acta, 2006, 359, 1705.

35. T. Hughbanks and R. Hoffmann, J. Am. Chem. Soc., 1983, 105, 1150.

36. D. Mery, L. Plault, C. Ornelas, J. Ruiz, S. Nlate, D. Astruc, J. C. Blais, J. Rodrigues, S. Cordier, K. Kirakci and C. Perrin, Inorg. Chem., 2006, 45, 1156.

37. G. Prabusankar, Y. Molard, S. Cordier, S. Golhen, Y. Le Gal, C. Perrin, S. Kalal, J. F. Halet and L. Ouahab, Eur. J. Inorg. Chem., 2009, 14, 2153.

38. Y. Molard, F. Dorson, V. Cîrcu, T. Roisnel, F. Artzner and S. Cordier, Angew. Chem. Int. ed., 2010, 49, 3351.

39. B. Fabre, S. Cordier, Y. Molard, C. Perrin, S. Ababou-Girard and C. Godet, J. Phys. Chem. C, 2009, 113, 17437.

40. A. W. Maverick and H. B. Gray, J. Am. Chem. Soc. 1981, 103, 1298.

41. A. W. Maverick, J. S. Najdzionek, D. MacKenzie, D. G. Nocera and H. B. Gray, J. Am. Chem. Soc. 1983, 105, 1878.

42. D. G. Nocera and H. B. Gray, J. Am. Chem. Soc. 1984, 106, 824. 
43. F. Grasset, F. Dorson, S. Cordier, Y. Molard, C. Perrin, A.-M. Marie, T. Sasaki, H. Haneda, Y. Bando and M. Mortier, Adv. Mater., 2008, 20, 143.

44. F. Grasset, Y. Molard, F. Dorson, S. Cordier, M. Mortier, V. Demange, C. Perrin, V. Marchi-Artzner and H. Haneda, Chem. Commun., 2008, 39, 4729.

45. K. Kirakci, S. Cordier and C. Perrin, Z. Anorg. Allg. Chem., 2005, 631, 411.

46. H. Schaefer, H. G. Schnering, J. Tillack, F. Kuhnen, H. Woehrle and H. Baumann, Z. Anorg. Allg. Chem., 1967, 353, 281.

47. W. Stöber, A. Fink and E. Bohn, J. Colloid Interface Sci., 1968, 26,62.

48. S. Reculusa and S. Ravaine, Chem. Mater., 2003, 15, 598.

49. A. Taflove and S. C. Hagness, Computational Electrodynamics: The Finite-Difference Time-Domain Method, 3rd ed.; Artech House, Inc.: Norwood, MA, 2005.

50. A. Farjadpour, D. Roundy, A. Rodriguez, M. Ibanescu, P. Bermel, J. D. Joannopoulos, S. G. Johnson and G. Burr, Opt. Lett., 2006, 31, 2972. 


\section{Figures captions}

Figure 1. a) Representation of a $\mathrm{Mo}_{6} \mathrm{~L}_{8}^{\mathrm{i}} \mathrm{L}_{6}^{\mathrm{a}}$ cluster unit. The $\mathrm{Mo}_{6}$ cluster is represented as a grey octahedron. Apical ligands $\left(\mathrm{L}^{\mathrm{a}}\right)$ are in terminal positions and inner ligands $\left(\mathrm{L}^{\mathrm{i}}\right)$ are in face-capping position; b) TEM image of the 270 nm $\mathrm{Cs}_{2} \mathrm{Mo}_{6} \mathrm{Br}_{14} @ \mathrm{SiO}_{2}$ particles.

Figure 2. a) Concentration dependence of the photoluminescence spectra of the $330 \mathrm{~nm}$ $\mathrm{Cs}_{2} \mathrm{Mo}_{6} \mathrm{Br}_{14} @ \mathrm{SiO}_{2}$ particles in water; b) SEM side view of a colloidal crystal composed of 25 layers of $330 \mathrm{~nm} \mathrm{Cs}_{2} \mathrm{Mo}_{6} \mathrm{Br}_{14} @ \mathrm{SiO}_{2}$ particles. c) Angle dependence of the extinction (at $\alpha=$ $\left.0^{\circ}\right) /$ reflection (for larger angles) experimental and simulated spectra of the engineered colloidal structure; d) Angle dependence of the extinction (at $\alpha=0^{\circ}$ ) / reflection (for larger angles) and corresponding photoluminescence spectra of the engineered colloidal structure. In c), the grey rectangle represents the spectral range of the emission peak of the $\mathrm{Cs}_{2} \mathrm{Mo}_{6} \mathrm{Br}_{14} @ \mathrm{SiO}_{2}$ particles.

Figure 3. a) SEM side view of a colloidal crystal composed by one layer of $460 \mathrm{~nm}$ $\mathrm{Cs}_{2} \mathrm{Mo}_{6} \mathrm{Br}_{14} @ \mathrm{SiO}_{2}$ spheres embedded between two stacks of five layers of $330 \mathrm{~nm}$ $\mathrm{Cs}_{2} \mathrm{Mo}_{6} \mathrm{Br}_{14} @ \mathrm{SiO}_{2}$ particles. b) Angle dependence of the extinction (at $\alpha=0^{\circ}$ ) $/$ reflection (for larger angles) experimental and simulated spectra of the engineered colloidal structure. c) Angle dependence of the extinction (at $\alpha=0^{\circ}$ ) / reflection (for larger angles) and corresponding photoluminescence spectra of the engineered colloidal structure. d) Emission spectra of the $(330)_{5} /(460)_{1} /(330)_{5}$ crystal divided by the emission from a $(270)_{10}$ reference crystal. The downward arrows indicate the positions of the dielectric and air bands while the upward arrows indicate the positions of the pass band. In b), the grey rectangle represents the spectral range of the emission peak of the $\mathrm{Cs}_{2} \mathrm{Mo}_{6} \mathrm{Br}_{14} @ \mathrm{SiO}_{2}$ particles. 
Figure 4. a) SEM side view of a $\mathrm{A}(\mathrm{BA})_{3}$ heterostructure. b) Experimental extinction (at $\alpha=$ $\left.0^{\circ}\right)$ (dashed lines) and photoluminescence spectra (solid lines) of the $\mathrm{A}(\mathrm{BA})_{1}$ (black curves) and $\mathrm{A}(\mathrm{BA})_{3}$ (grey curves) heterostructures. Spectra are vertically shifted for better clarity. 
a)

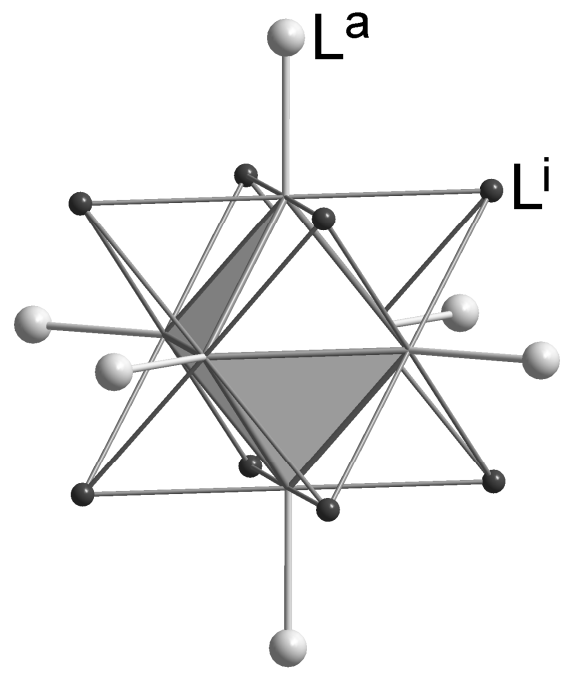

b)

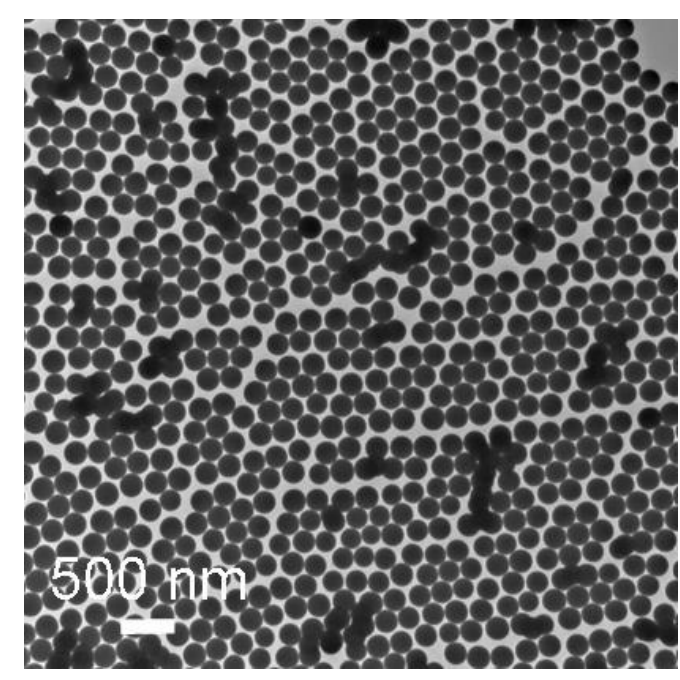

Figure 1. 
a)

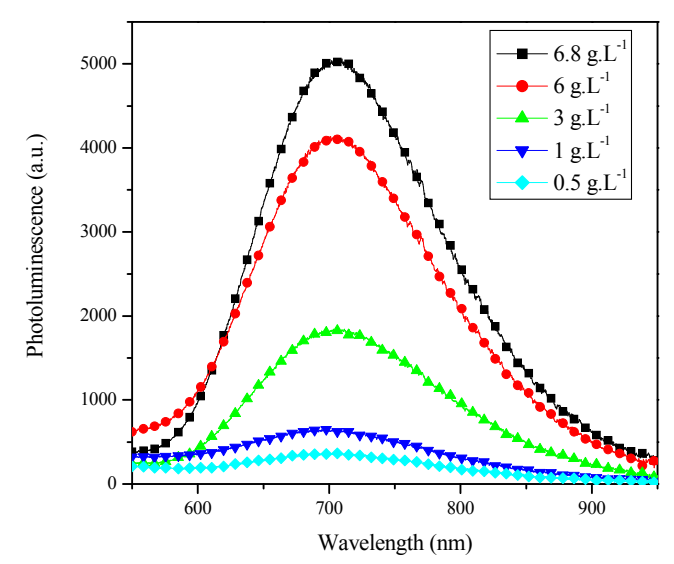

c)

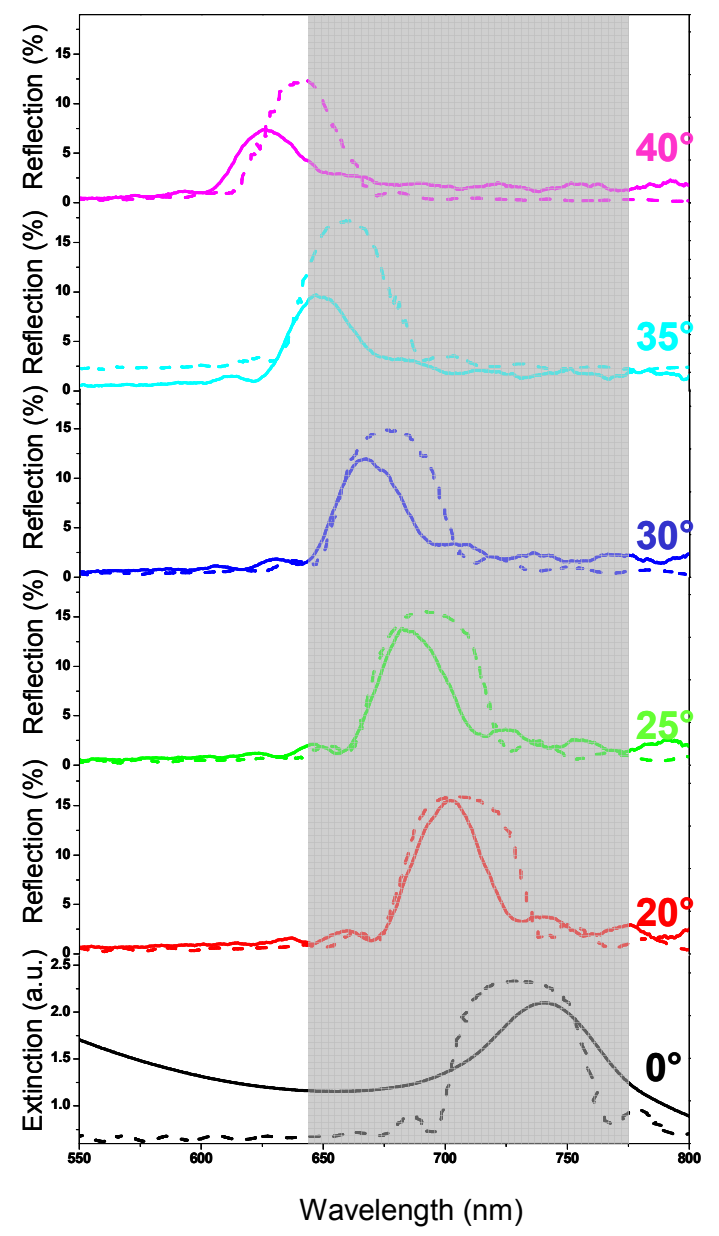

b)

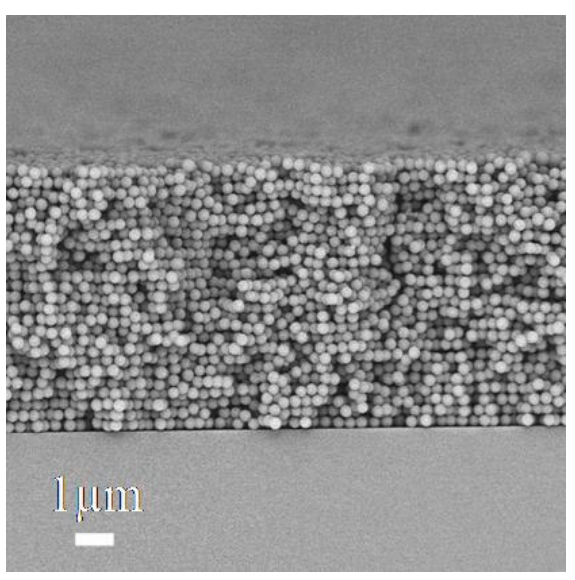

d)

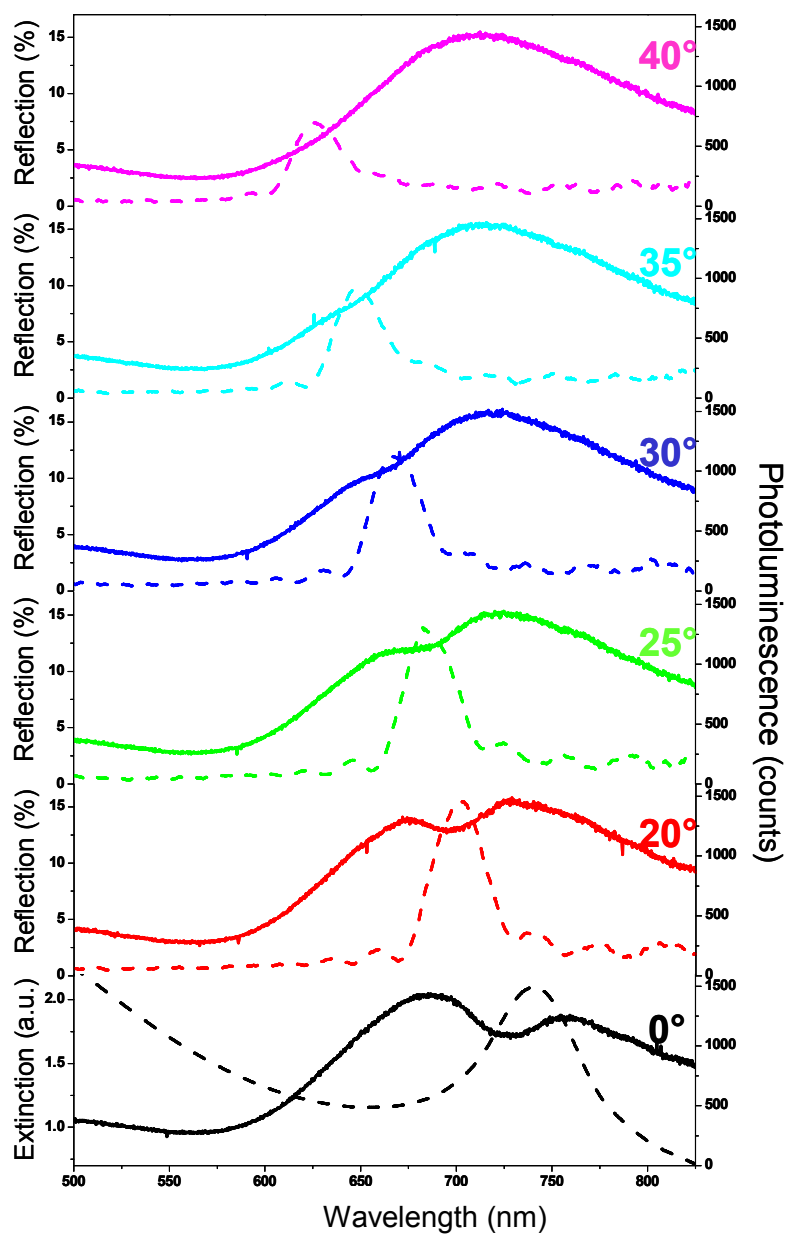

Figure 2. 
a)

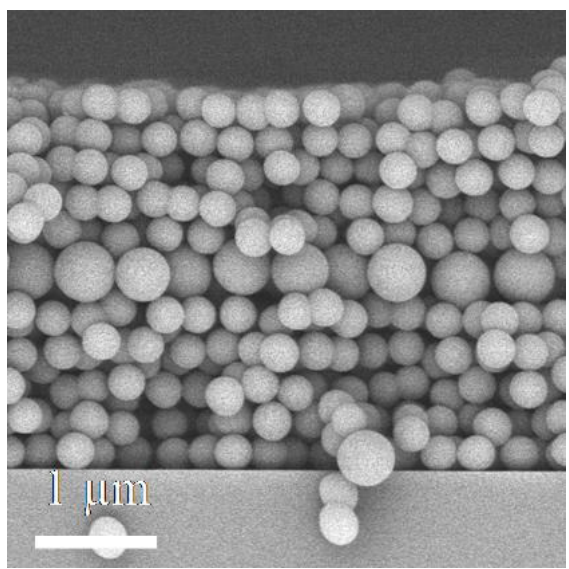

b)

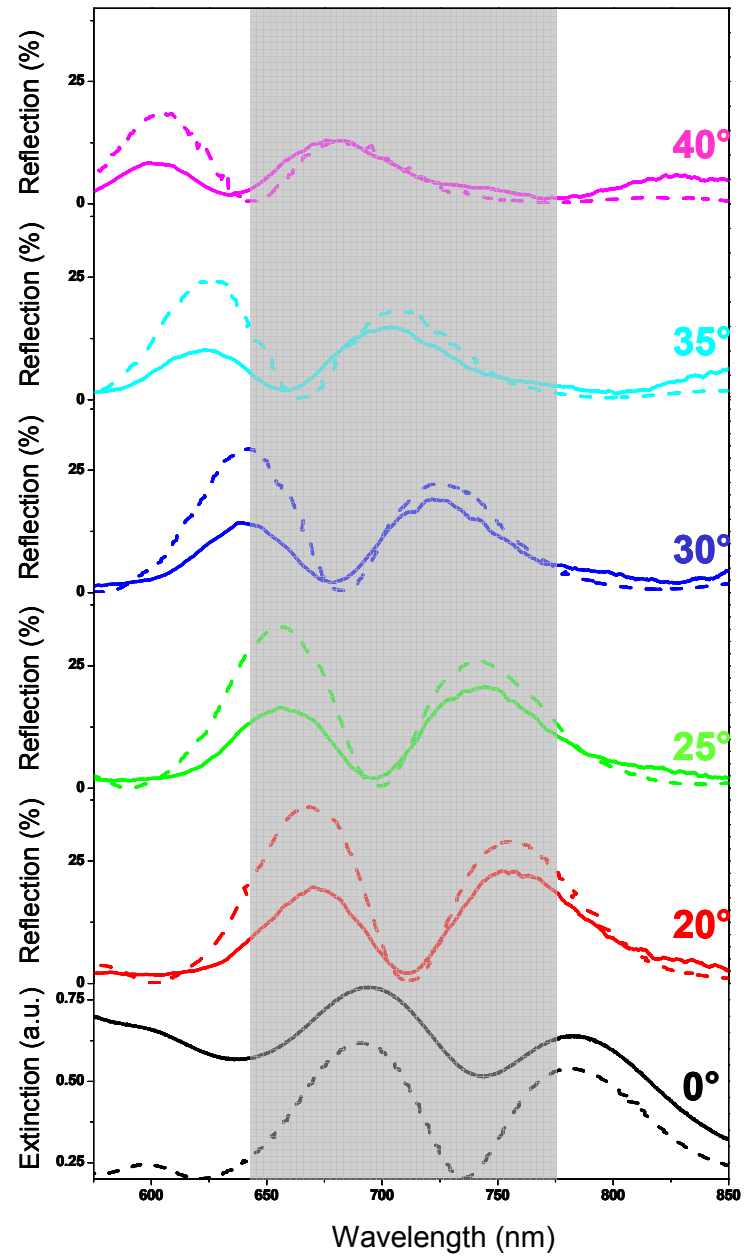

Figure 3 
c)

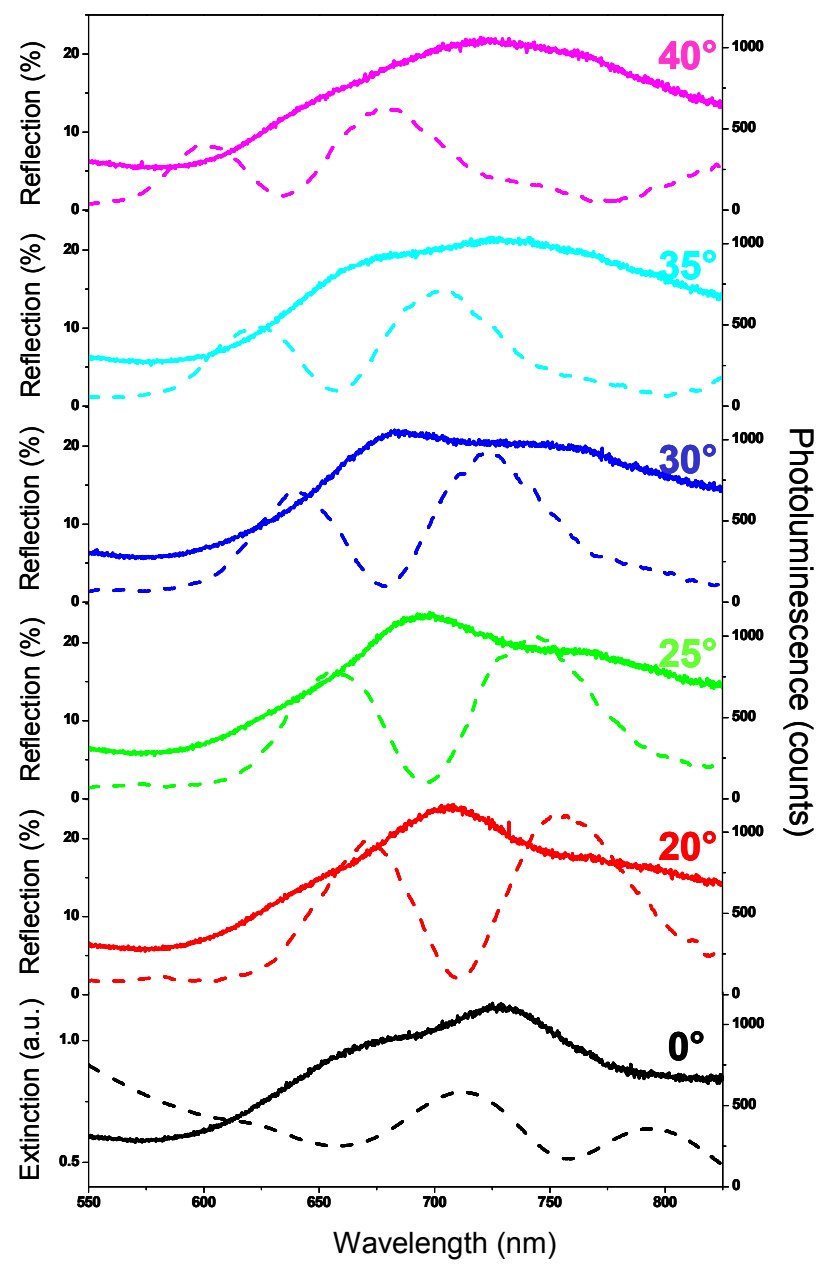

d)

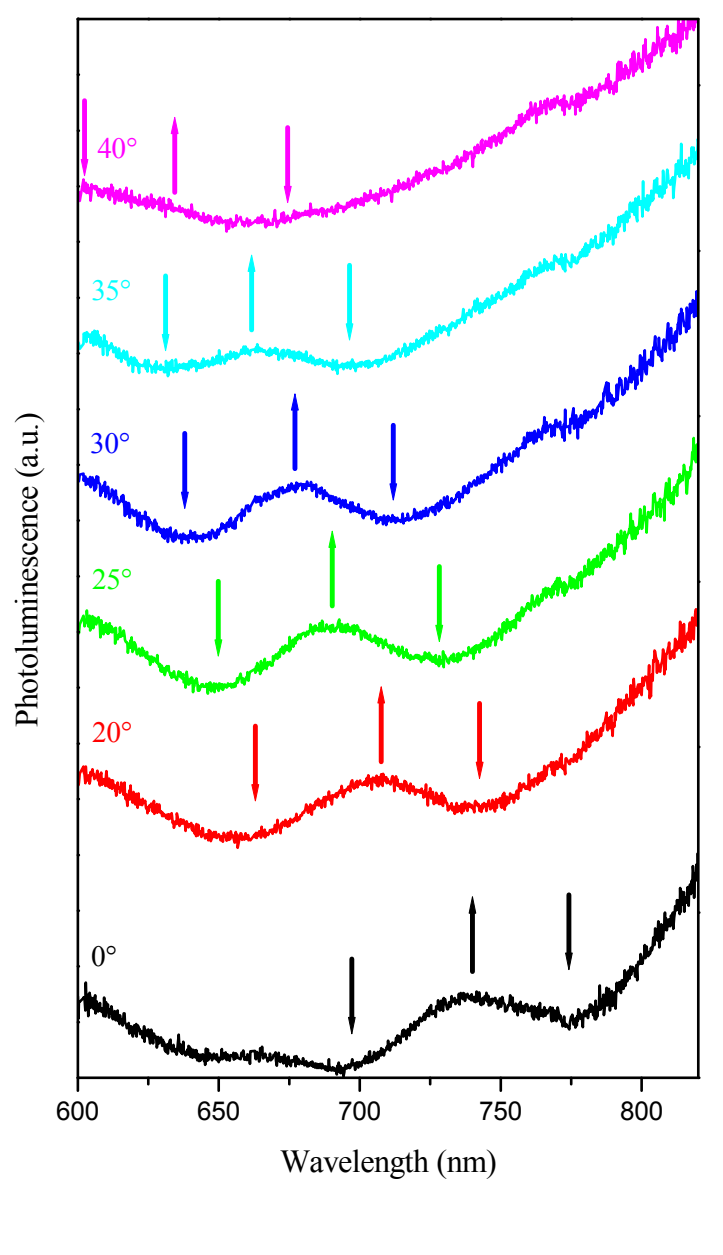

Figure 3. 
a)

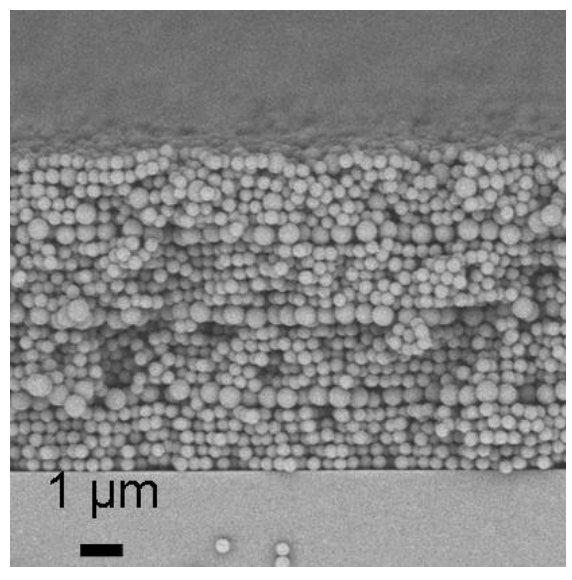

b)

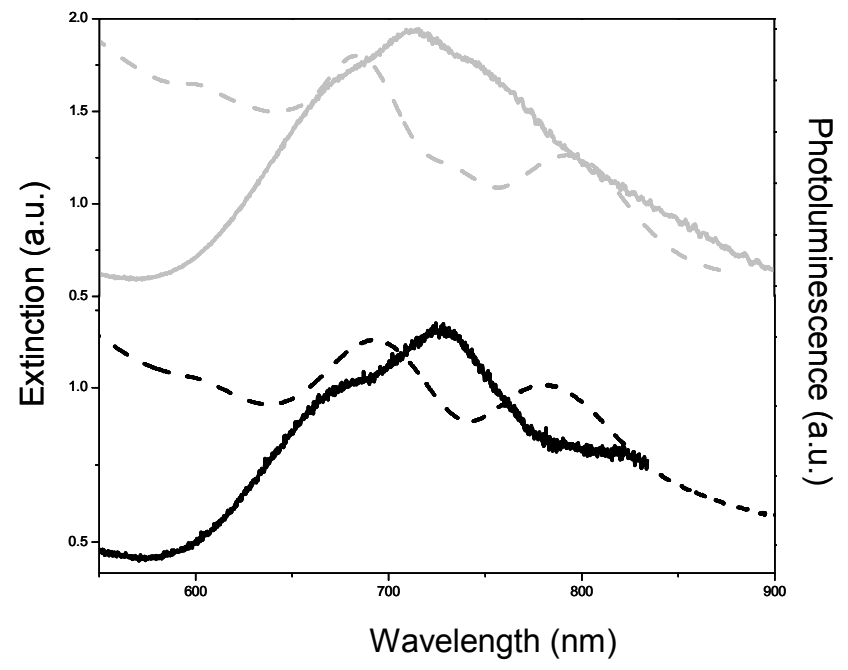

Figure 4. 